\title{
Histomorphometric study of role of lactoferrin in atrophy of the intestinal mucosa of rats
}

\author{
M. Caruso ${ }^{1}$, A. Demonte ${ }^{2}$, V. A. Neves ${ }^{2 *}$ \\ ${ }^{1}$ UNIARA - University Centre of Araraquara, Araraquara, Brazil \\ ${ }^{2}$ Department of Food and Nutrition, School of Pharmaceutical Sciences, São Paulo State University—UNESP, Araraquara, Brazil; \\ *Corresponding Author: nevesva@fcfar.unesp.br
}

Received 2 October 2012; revised 18 November 2012; accepted 28 November 2012

\section{ABSTRACT}

The purpose of this work was to study the effects of oral administration of lactoferrin (Lf) in rats subjected to atrophy of the small intestine induced by a diet based on soy protein concentrate as the main protein source. We used 24 male Wistar rats aged $\mathbf{4 0}$ days, kept in individual cages under appropriate conditions of temperature, light and humidity. The animals were divided into four groups $(n=6)$; 1) group SL received soy-based food and, once a day, a supplement of $200 \mathrm{mg} / \mathrm{kg}$ of Lf administered by gavage; 2) group Si received the soy feed without supplement of $L f ; 3)$ group $C L$ received a diet based on casein plus Lf; 4) group $\mathrm{Ci}$ received the casein diet without supplement of Lf. At the end of fifteen days, a $10 \mathrm{~mm}$ segment of the initial portion of the small intestine was sectioned and subjected to morphometry of the intestinal crypts and villi and assessment of the number and size of myofibroblasts. Comparison between groups showed that the length of the villi was similar in groups $\mathrm{Ci}$ and $\mathrm{CL}$ and higher in $\mathrm{CL}$ than in SL; SL than in $\mathrm{Si}$, in Ci than in SL, and in $\mathrm{Ci}$ than in Si to $\mathrm{Ci}$. The crypt depth was similar in $S L$ and $C L, S L$ and $C i$ and $C i$ and $C L$ and was higher in Si than in $\mathrm{Ci}$ and in Si than in SL. The number of myofibroblasts was higher in SL than in $\mathrm{CL}$, in $\mathrm{SL}$ than in $\mathrm{Si}$, in $\mathrm{CL}$ than in $\mathrm{Ci}$, and in $\mathrm{SL}$ than in and $\mathrm{Ci}$; between $\mathrm{Ci}$ and $\mathrm{Si}$ there was no difference. The area of myofibroblasts was similar between the groups $S L$ and $C L$ and $S i$ and $C i$ and higher in SL than in Si, and in $\mathrm{Cl}$ than in and $\mathrm{Ci}$, and in $\mathrm{SL}$ than in Ci. All statistical analysis assumed significance when $p<0.05$. From these results, we conclude that lactoferrin increases the number and size of the pericrypt myofibroblasts and stimulates rapidly the regeneration of atrophied villi.
Keywords: Intestinal Villi; Lactoferrin; Myofibroblast; Atrophy

\section{INTRODUCTION}

The basic functional unit of absorption in the intestine is the "crypt-villus". Enterocytes proliferate in the crypt and migrate toward the top of the villi where they are discarded at the end of their useful life. The reproduction rate of these cells in the crypt and the rate migration may be altered in various physiological or pathological states and also by the action of various substances [1]. Nutritional factors may be directly responsible for altering the intestinal mucosa [2]. The gut-nutrient relationship is extremely complex and involved, where even the mere presence or absence of nutrients in the intestinal lumen may induce changes or adaptations, such as atrophy or hypertrophy of the mucosa. There are reports that soybean meal can cause an increase in villous atrophy and some authors assume those immunologically active proteins, such as glycinin and $\beta$-conglycinin, are responsible for hypersensitivity reactions, and thus cause villous atrophy [3]. Feeding pigs on a diet with soybean meal as the sole source of protein, or on "corn/soy" diets for pigs, resulted in a lower villus height in the middle portion of the small intestine, as well as deeper in all areas of the small intestine [4], compared to diet with casein as the main protein observed by Caruso and Demonte [5] in rats subjected to dietary soy protein concentrate as the sole protein source.

Lactoferrin (Lf) is a glycoprotein belonging to the transferring group well recognized for its antimicrobial action and also for promoting cell growth and differentiation [6]. The molecular mechanisms by which lactoferrin acts at the cellular level are largely unknown, but specific receptors for lactoferrin have been described in various cell types and tissues of mammals, such as monocytes, lymphocytes, platelets, liver, epithelial cells of the mammary glands and intestines [7]. Some studies have shown the involvement of this protein in stimulating 
the growth of epithelial cells such as keratinocytes [8], enterocytes in Caco-2 culture [9], epithelium of the intestinal lymphoid tissue [10] and endometrial stromal cells [11]. Similar actions have also been demonstrated for cells of mesodermal origin, such as osteoblasts [12], lymphoblastic T cells [13] and also in angiogenesis [14]. Myofibroblasts (Mf), cells of mesodermal origin, which are differentiated fibroblasts that have been to express smooth muscle cell phenotype, are often located beneath the skin, as well as at the edge of the crypts and in the lamina propria of intestinal villi. They are the source of various cell growth factors, such as FGF (Fibroblast Growth Factor) and HGF (Hepatocyte Growth Factor), and also of basement membrane proteins [15].

Our experiment had the objective of determining the possible influence of oral administration of lactoferrin on the sub-epithelial pericrypt sheath myofibroblasts and the repopulation of the intestinal mucosa of rats, atrophied by the use of soy as the only source of protein.

\section{MATERIALS AND METHODS}

\subsection{Animals}

A total of 24 male albino Wistar rats, aged 40 days, average weight of $123.8 \pm 1.2$ grams, were allowed to adapt for three days, with free access to commercial feed (Labina $^{\circledR}$, Purina, Brazil) and water under the following conditions: forced ventilation, controlled humidity and temperature $\left(50 \%-60 \% \mathrm{RH}\right.$ and $\left.22^{\circ} \mathrm{C} \pm 1{ }^{\circ} \mathrm{C}\right)$, and a 12:12 $\mathrm{h}$ light and dark cycle. After adaptation, the animals were first weighed and separated into four groups of six animals, identified and transferred to individual cages. The four groups $(n=6)$ received different types of feed, with or without supplements of lactoferrin and were identified with the following codes: $\mathrm{Ci}$ (casein alone), $\mathrm{CL}$ (casein plus lactoferrin), Si (soybean alone); and SL (soybean plus lactoferrin). The weighing was repeated on the fifth, tenth and fifteenth day of the experiment.

\subsection{Diets}

Diets were prepared in compliance with the American Institute of Nutrition (AIN-93) recommendations [16]. Each animal received $10 \mathrm{~g}$ of their daily diet (AIN-93) and water ad libitum. All procedures were performed in accordance with the Guide for the Care and Use of Laboratory Animals [17]. Groups CL and SL received $200 \mathrm{mg} / \mathrm{kg}$ lactoferrin (Bioferrin $1000^{\circledR}$, Apolactoferrin, Glanbia Nutritionals, Carlsbad, USA) dissolved in 1.0 $\mathrm{mL}$ of distilled water $(200 \mathrm{mg} / \mathrm{mL})$ by gavage, once daily. The dose and method of administration were based on other experiments [18-21].

\subsection{Experimental Procedure}

For fifteen days, group SL ate a feed with soya as the only protein source and received the lactoferrin by gavage once a day, while group $\mathrm{Si}$ received the soy diet without the lactoferrin. A third group (CL) received a diet with casein as only protein source and lactoferrin by gavage, while the last group $(\mathrm{Ci})$ received the casein diet without lactoferrin.

\subsection{Surgical Procedure}

At the end of fifteen days the animals were anesthetized with ketamine $(50 \mathrm{mg} / \mathrm{kg}) /$ xylazine $(5 \mathrm{mg} / \mathrm{kg})$. Each animal was subjected to trichotomy of the ventral region and antisepsis with $1 \%$ povidone-iodine solution. By laparotomy, a $10 \mathrm{~mm}$ long segment was sectioned from the initial portion of the small intestine, $4 \mathrm{~cm}$ from the xiphoid process, $15 \mathrm{~mm}$ from the gastro-duodenal junction and termino-terminal anastomosis was performed with the edges of the bowel, for its use in another experiment. The sectioned segments of intestines were examined by conventional histological techniques for histomorphometry of the villi and intestinal crypts and immunohistochemistry to assess of the number and size of the myofibroblasts. The experimental procedure was approved by the Ethics Committee for Animal Use in Research (CEUA), Faculty of Pharmaceutical Sciences UNESP (res. 06/2011).

\subsection{Treatment of Collected Material}

After being fixed in 10\% formaldehyde (in $\mathrm{pH} 7.5$ buffer), the segments were subjected to the standard technique of dehydration in increasing battery of ethyl alcohol, xylene and embedded in paraffin wax. Thin sections ( $4 \mu \mathrm{m}$ thick) were cut in the conventional microtome, and laid on both untreated and silanized microscope slides. For the observation and measurement of intestinal villi and crypts, slide were stained with Hematoxylin and Eosin (HE). The Avidin-Biotin Peroxidase (ABP) immunohistochemical technique devised by $\mathrm{Hsu}$ et al. [22] was used to reveal myofibroblasts. This indicates, in brown tones, the presence of these cells. The silanized slides were used for good adhesion of the histological sections. After dewaxing and rehydration of the sections, the slides were immersed in citrate buffer $(\mathrm{pH}$ 6.0) exposed to microwave oven for 15 minutes, then transferred to phosphate buffer with hydrogen peroxide + $3 \%$ methanol for 20 minutes, to block endogenous peroxidase. Slides were incubated in primary antibody anti$\alpha$-smooth muscle actin (Monoclonal Mouse Smooth Muscle Actin Clone 1A4 Code M0851, Dako Cytomation, USA) for 12 hours at $4^{\circ} \mathrm{C}$. After washing in phosphate buffer, biotinylated antibody was applied to the slides for 30 minutes at room temperature. After another bath in phosphate buffer, we applied the complex streptavidin/peroxidase for 30 minutes, at room temperature. 
The slides were again washed in phosphate buffer, treated with diaminobenzene to reveal the immune reaction and counterstaining with hematoxylin.

\subsection{Analysis of Slides}

Observations and measurements were taken with an Olympus BX 50 optical microscope (Olympus America Inc., USA), at magnifications $100 \times$ and $400 \times$, in three different fields. The images were captured by a Sony SSC-DC54 digital camera (Sony Electronics Inc., Japan) and sent to a Pentium IV computer equipped with an E1940 LG Flatron monitor (LG Electronics, USA). All measurements were performed with the program ImageJ $1.44 p$ (Natl. Inst. of Health, USA). The Length of the Villus (LV) was measured from its basal region, which coincides with the top of the crypts. A line was drawn between two points on the base and another line perpendicular to it, toward the point at the apex of the villus. The length of the second line, in $\mu \mathrm{m}$, provided by the image analyzer, was taken as the length of the villus (Figure 1). The depth of the crypt (DC) was measured from its base to the crypt-villus transition. These structures were measured on both sides (right and left) of the cut, to reduce, by averaging, any changes in measurement due to a possible tilt of the material during embedding of the segment in wax. For each animal, 160 villi and 80 crypts were measured giving a total of 960 villi and 480 crypts for each diet group. The number of myofibroblasts was determined by direct counting. Areas of myofibroblasts were extracted by ImageJ $1.44 p$, from the images by individually marking them by means of the Freehand Select tool, as shown in Figure 2.

\subsection{Statistical Analysis}

Two-way Analysis of Variance (ANOVA) for repeated measures was used, with a significance level (alpha) $p \leq$ 0.05 , to compare the values obtained in the measurement of all villi and crypts on both sides of the section, instead of simply taking the value. The weights of animals in

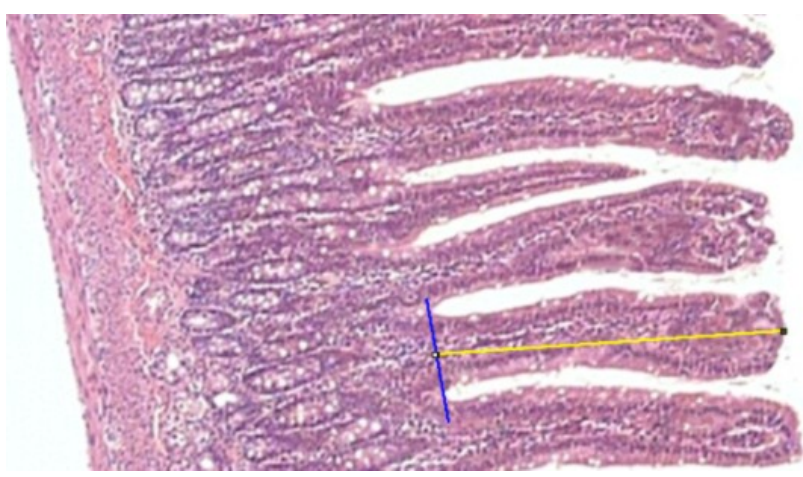

Figure 1. Measurement $(\mu \mathrm{m})$ of the length of a villus with the straight line tool of ImageJ. (Magnificatiion: 100×).

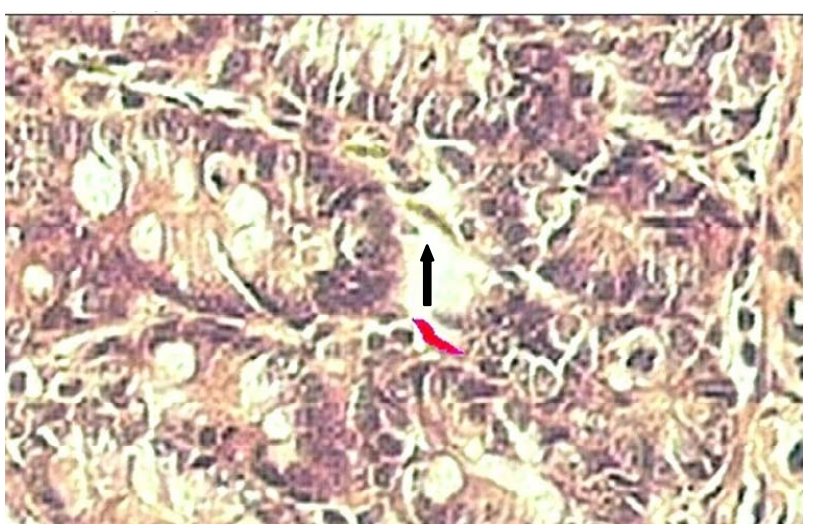

Figure 2. Determination of the total area $\left(\mu \mathrm{m}^{2}\right)$ of the myofibroblast pericrypt sheath, with the freehand selections tool, in ImageJ. Marked myofibroblast (red) and unmarked myofibroblasts (black arrow). (Magnification: 400×).

different groups were compared with the Student t-test, also at a significance level (alpha) $p \leq 0.05$. Linear Regression and Correlation analysis were used to compare the values obtained for the variables studied. The software used was PAST 1.99, Excel (Microsoft Co.) and BioEstat 5.0.

\section{RESULTS}

Animal weight (g): the Student t-test showed that the means on the first day were similar in all groups $(p>$ 0.05 ). On the fifth day, there was a very significant difference between groups $\mathrm{Ci}$ and $\mathrm{Si}$ favoring the casein group $(p<0.001)$. Between groups $\mathrm{CL}$ and $\mathrm{SL}$, the weight of casein group was again higher $(p=0.001)$. Comparing groups SL and Si showed a significantly higher weight for the lactoferrin group $(p<0.05)$. Between groups $\mathrm{Ci}$ and $\mathrm{SL}$, the comparison was favorable to the casein group $(p=0.001)$. There was no significant difference between the groups $\mathrm{CL}$ and $\mathrm{Ci}$. On the tenth day, comparisons between groups CL and SL, Ci and SL and $\mathrm{CL}$ and $\mathrm{Ci}$ showed no significant difference. Between groups $\mathrm{Ci}$ and $\mathrm{Si}$ the casein group showed more growth $(p<0.001)$. The groups SL and Si showed a highly significant difference, favorable to the lactoferrin group $(p<0.001)$. On the fifteenth day, there was a very significant difference between the groups $\mathrm{Ci}$ and $\mathrm{Si}$, the casein group having grown more $(p<0.001)$, while groups SL and Si showed a highly significant difference favor of the lactoferrin group $(p<0.001)$. No differences were observed between groups $\mathrm{Ci}$ and $\mathrm{CL} ; \mathrm{CL}$ and $\mathrm{SL}$ or $\mathrm{Ci}$ and SL The average weights of the groups are compared in Table 1.

\subsection{Length (Height) of Villi (LV)}

The comparisons between groups are shown in Table 2. Comparisons between the groups $\mathrm{Ci}$ and $\mathrm{Si}$, between 
Table 1. Intergroup ${ }^{1}$ comparisons of mean body weight $(\mathrm{g})$.

\begin{tabular}{|c|c|c|c|c|c|c|}
\hline Group & PA5 & $p$ & PA10 & $p$ & PA15 & $p$ \\
\hline SL & $128.15 \pm 1.01$ & 0.001 & $142.84 \pm 1.15$ & 0.134 & $154.89 \pm 1.24$ & $>0.05$ \\
\hline CL & $133.22 \pm 1.30$ & & $145.38 \pm 1.42$ & & $155.42 \pm 1.52$ & \\
\hline Si & $125.83 \pm 1.05$ & 0.0001 & $134.38 \pm 0,91$ & $5.43 \mathrm{E}-06$ & $140.11 \pm 1.17$ & $<0.001$ \\
\hline $\mathbf{C i}$ & $131.75 \pm 0.65$ & & $144.96 \pm 0,72$ & & $155.01 \pm 0.77$ & \\
\hline SL & $128.15 \pm 1.01$ & 0.01 & $142.84 \pm 1.15$ & $2.65 \mathrm{E}-06$ & $154.89 \pm 1.24$ & $<0.001$ \\
\hline $\mathrm{Si}$ & $125.83 \pm 1.05$ & & $134.38 \pm 0.91$ & & $140.11 \pm 1.17$ & \\
\hline CL & $133.22 \pm 1.30$ & 0.110 & $145.38 \pm 1.42$ & 0.634 & $155.42 \pm 1.52$ & $>0.05$ \\
\hline $\mathbf{C i}$ & $131.75 \pm 0.65$ & & $144.96 \pm 0.72$ & & $155.01 \pm 0.77$ & \\
\hline $\mathbf{C i}$ & $131.75 \pm 0.65$ & 0.001 & $144.96 \pm 0.72$ & 0.119 & $155.01 \pm 0.77$ & $>0.05$ \\
\hline SL & $128.15 \pm 1.01$ & & $142.84 \pm 1.15$ & & $154.89 \pm 1.24$ & \\
\hline
\end{tabular}

${ }^{1}$ PA5, PA10 and PA15 = mean animal weights in grams, on the 5th, 10th and 15 th days respectively. $p=$ value of probability. Ci (casein alone), CL (casein plus lactoferrin), Si (soybean alone), and SL (soybean plus lactoferrin).

Table 2. Intergroup ${ }^{1}$ comparisons of mean Villus Length (LV) in $\mu \mathrm{m}$.

\begin{tabular}{ccc}
\hline Groups & MLV \pm SD & $p$ \\
\hline SL & $205.75 \pm 32.5$ & $<\mathbf{0 . 0 0 1}$ \\
$\mathbf{C L}$ & $236.3 \pm 33.2$ & \\
$\mathbf{S i}$ & $154.9 \pm 31.7$ & $<\mathbf{0 . 0 0 1}$ \\
$\mathbf{C i}$ & $235.0 \pm 32.5$ & \\
$\mathbf{S L}$ & $205.5 \pm 32.5$ & $<\mathbf{0 . 0 0 1}$ \\
$\mathbf{S i}$ & $154.9 \pm 31.7$ & \\
$\mathbf{C i}$ & $235.0 \pm 32.5$ & $<\mathbf{0 . 0 0 1}$ \\
$\mathbf{S L}$ & $205.5 \pm 32.5$ & \\
$\mathbf{C L}$ & $236.3 \pm 33.2$ & $>\mathbf{0 . 0 5}$ \\
$\mathbf{C i}$ & $235.0 \pm 32.5$ &
\end{tabular}

${ }^{1} \mathrm{MLV} \pm \mathrm{SD}=$ mean Villus Length $(\mathrm{LV}) \pm$ standard deviation of the animal group. $p=$ value of probability. Ci (casein alone), CL (casein plus lactoferrin), Si (soybean alone), and SL (soybean plus lactoferrin).

CL and SL and between Ci and SL all showed that the length of the villi was significantly higher in animals fed casein than in those fed soybean $(p<0.001)$. In the comparison between groups $\mathrm{Si}$ and SL, LV was significantly higher in animals that received lactoferrin supplementation $(p<0.001)$. There was no significant difference in $\mathrm{LV}$ between the groups $\mathrm{Ci}$ and $\mathrm{CL}$.

\subsection{Depth of Crypts (DC)}

Table 3 compares the increased Depths of the Crypts (DC), in micrometers $(\mu \mathrm{m})$, between pairs of groups. The comparison between $\mathrm{Ci}$ and $\mathrm{Si}$ indicates that the depths of the crypts are significantly different between the two protein sources, being greater for animals fed soy. In the
Table 3. Intergroup ${ }^{1}$ comparisons of mean crypt depth (PD) in $\mu \mathrm{m}$.

\begin{tabular}{ccc}
\hline Groups & MDC \pm SD & $\boldsymbol{p}$ \\
\hline SL & $52.83 \pm 11.98$ & $>\mathbf{0 . 0 5}$ \\
CL & $48.73 \pm 11.80$ & \\
Si & $116.94 \pm 37.57$ & $<\mathbf{0 . 0 0 1}$ \\
Ci & $50.34 \pm 11.98$ & \\
SL & $52.83 \pm 11.98$ & $<\mathbf{0 . 0 0 1}$ \\
Si & $116.94 \pm 37.57$ & \\
CL & $48.73 \pm 11.80$ & $>\mathbf{0 . 0 5}$ \\
$\mathbf{C i}$ & $50.34 \pm 11.98$ & \\
$\mathbf{C i}$ & $50.34 \pm 11.98$ & $>\mathbf{0 . 0 5}$ \\
SL & $52.83 \pm 11.98$ & \\
\hline
\end{tabular}

${ }^{1} \mathrm{MDC} \pm \mathrm{SD}=$ mean of the Crypt Depth $(\mathrm{DC}) \pm$ standard deviation of the animal group. $p=$ value of probability. Ci (casein alone), CL (casein plus lactoferrin), Si (soybean alone), and SL (soybean plus lactoferrin).

comparison between the groups $\mathrm{SL}$ and $\mathrm{Si}, \mathrm{DC}$ was significantly higher in animals without lactoferrin supplementation $(p<0.001)$. The comparisons between the groups $\mathrm{CL}$ and $\mathrm{SL} ; \mathrm{CL}$ and $\mathrm{Ci}$ and $\mathrm{Ci}$ and SL showed no significant difference.

\subsection{Number of Myofibroblasts (NMF)}

In Table 4, the comparison between groups $\mathrm{Ci}$ and $\mathrm{Si}$ shows no significant differences, indicating that the type of dietary protein does not interfere in the number of myofibroblasts. In the table, comparing the groups SL and $\mathrm{Si}, \mathrm{CL}$ and $\mathrm{Ci}$ and $\mathrm{Ci}$ and $\mathrm{SL}$, a value of $p<0.001$ is observed, a highly significant difference indicating that supplementing the soy or casein diet with lactoferrin 
Table 4. Intergroup ${ }^{1}$ comparisons of mean Numbers of Myofibroblasts (MNMf).

\begin{tabular}{ccc}
\hline Groups & MNMf \pm SD & $\boldsymbol{p}$ \\
\hline SL & $6.31 \pm 1.57$ & $<\mathbf{0 . 0 0 1}$ \\
$\mathbf{C L}$ & $5.52 \pm 1.48$ & \\
$\mathbf{S i}$ & $4.26 \pm 1.30$ & $>\mathbf{0 . 0 5}$ \\
$\mathbf{C i}$ & $4.38 \pm 1.54$ & \\
SL & $6.31 \pm 1.57$ & $<\mathbf{0 . 0 0 1}$ \\
Si & $4.26 \pm 1.30$ & \\
$\mathbf{C L}$ & $5.52 \pm 1.48$ & $<\mathbf{0 . 0 0 1}$ \\
$\mathbf{C i}$ & $4.38 \pm 1.54$ & \\
$\mathbf{C i}$ & $4.38 \pm 1.54$ & $<\mathbf{0 . 0 0 1}$ \\
$\mathbf{S L}$ & $6.31 \pm 1.57$ & \\
\hline
\end{tabular}

${ }^{1} \mathrm{MNMf} \pm \mathrm{SD}=$ mean Number of Myofibroblasts $(\mathrm{NMf}) \pm$ standard deviation of the animal group. $p=$ value of probability. $\mathrm{Ci}$ (casein alone), $\mathrm{CL}$ (casein plus lactoferrin), Si (soybean alone), and SL (soybean plus lactoferrin).

increase the number of myofibroblasts.

\subsection{Area of Myofibroblasts (AMF)}

Comparisons of the areas of myofibroblasts between the groups are shown in Table 5. Highly significant values $(p<0.001)$ were obtained for the comparisons between groups $\mathrm{SL}$ and $\mathrm{Si}$ and $\mathrm{CL}$ and $\mathrm{Ci}$, while $\mathrm{Ci}$ and $\mathrm{SL}$ also differed $(p<0.01)$. Between the groups SL and CL and between $\mathrm{Si}$ and $\mathrm{Ci}$ comparisons showed no significant differences. Thus, AMF was not affected by the dietary protein, but the lactoferrin supplement increased the total myofibroblast area significantly.

\section{DISCUSSION}

A large number of studies of the role of lactoferrin in the intestinal mucosa have been related to the participation of this protein in the control of microorganisms, mainly related to the ability to transport iron and other metals $[6,23,24]$. Our experiment with its greater emphasis on cell proliferation assessed the role of lactoferrin with regard to the regeneration of intestinal villi undergoing atrophy. Hagiwara et al. [25] carried out experiments on cultured rat intestine cells and showed that bovine lactoferrin, associated with EGF (Epidermal Growth Factor), actively stimulates the proliferation of enterocytes.

\subsection{Weight of Animals}

On the fifth day, the difference between the groups $\mathrm{Ci}$ and $\mathrm{Si}$ can be explained by villous atrophy caused by the allergenicity of proteins and/or antinutritional factors in soy, which occurs within the first 24 hours after ingestion [26] and the consequent malabsorption of nutrients. The
Table 5. Intergroup ${ }^{1}$ comparisons of mean total Areas of the Myofibroblasts (AMf) in $\mu \mathrm{m}^{2}$.

\begin{tabular}{ccc}
\hline Groups & MAMf \pm SD & $\boldsymbol{p}$ \\
\hline SL & $161.99 \pm 6.99$ & $>\mathbf{0 . 0 5}$ \\
$\mathbf{C L}$ & $164.13 \pm 6.47$ & \\
$\mathbf{S i}$ & $153.24 \pm 5.66$ & $>\mathbf{0 . 0 5}$ \\
$\mathbf{C i}$ & $152.85 \pm 4.43$ & \\
$\mathrm{SL}$ & $161.99 \pm 6.99$ & $<\mathbf{0 . 0 0 1}$ \\
$\mathbf{S i}$ & $153.24 \pm 5.66$ & \\
$\mathbf{C L}$ & $164.13 \pm 6.47$ & $<\mathbf{0 . 0 0 1}$ \\
$\mathbf{C i}$ & $152.85 \pm 4.43$ & \\
$\mathbf{C i}$ & $152.85 \pm 4.43$ & $<\mathbf{0 . 0 1}$ \\
$\mathbf{S L}$ & $161.99 \pm 6.99$ & \\
\hline
\end{tabular}

${ }^{1}$ MAMf \pm SD $=$ mean total Area of the Myofibroblasts (AMf) \pm standard deviation of the animal group. $p=$ value of probability. $\mathrm{Ci}$ (casein alone), CL (casein plus lactoferrin), Si (soybean alone), and SL (soybean plus lactoferrin).

same is valid for the comparison between groups CL and SL groups, although the difference between the average weights is less significant, which can be explained by a study of Conneely [27] that describes the anti-allergenic activity of lactoferrin as manifesting itself in a few hours. Also, lactoferrin may have shown some activity in villus repopulation. The difference between the groups SL and $\mathrm{Si}(p<0.05)$ in favor of lactoferrin, in this period indicates that this protein, in some ways, has a beneficial effect, improving the absorption of nutrients. The comparison between groups $\mathrm{CL}$ and $\mathrm{Ci}$ showed no significant difference, although the average weight is approximately $1.2 \%$ higher for the CL group. This can probably be explained by the fact that there are mechanisms that maintain homeostasis of the intestinal mucosa, preventing the hypoplasia or the opposite, the hyperplasia of the villi, both situations that can alter the degree of intestinal absorption [28]. The intrinsic mechanisms that regulate cell proliferation in the small intestine are not well understood. Studies on the replication of intestinal epithelial cells in vivo have suggested that the size of the villi regulates cell proliferation in the crypt, through a negative feedback control. May et al. [28] in an in vitro experiment with the IC- 6 cell line from the small intestine of rats, partially purified, a factor that inhibited DNA synthesis and the growth of these cells, was not cytotoxic and appeared to be specific for the intestinal epithelium. However, in an experiment using cultures of various strains of intestinal cells, Goke et al. [29] demonstrated that differentiated fibroblasts (myofibroblasts) often present in these culture models, regulate cell proliferation by paracrine action. More recently, Neunlist et al. [30], also in an in vitro experiment have shown that neuronal and glial components of the enteric nervous system, 
particularly the glial cells, could act together with other components of the mucosa, such as myofibroblasts, to enhance the control over cell proliferation in the intestinal epithelium and contribute to the maintenance of homeostasis.

\subsection{Histomorphometry of the Intestinal Mucosa}

The dimensions of the villi and crypts depict clearly the physiological or pathological conditions to which the digestive system is being subjected at a given time. As previously reported, there are numerous situations that can cause changes in the mucosa [2,5,31,32]. Various substances in different experiments have been shown to stimulate the increase in villus height and decrease in crypt depth decreased. King et al. [33] showed these effects using bovine colostrum in the diet of early weaned piglets. This result was expected, since colostrum is rich in cell growth factors, so that the whey is often used as a means of cell cultures. However, Lee et al. [34] showed that supplementation with combined swine Epidermal Growth Factor (EGF) and glutamine had no effect on intestinal development in early-weaned piglets. ReadSnyder et al. [35] also obtained similar result by adding selenium to the diet of chickens infected with reovirus. Another study by Garcia et al. [36], in which formic acid was associated with plant extracts showed similar results. Asfar et al. [37] showed that villous atrophy of the mucosa of rats, induced by fasting, was reversed to normal by the intake of green tea and also, to a lesser extent, by vitamin E. However, black tea did not show this effect.

In our experiment, the comparison between groups of animals fed on casein or soybean as the main protein source, supplemented with lactoferrin, shows exactly the behavior and response that the small intestine is capable of when subjected to different nutritional conditions. As expected, following an earlier study [5], comparison of the height of villi and depth of crypts, in the intestinal mucosa revealed highly significant differences between the groups without lactoferrin supplementation fed on casein $(\mathrm{Ci})$ and soybeans $(\mathrm{Si})$, corroborating reports in the literature, that soybeans, in the first instance, cause villous atrophy [26]. The opposite occurs in the depth of crypts, which show hyperplasia toward the submucosa in order to repopulate, by consecutive mitosis, their respective villi. Our experiment showed a highly significant difference between groups $\mathrm{Si}$ and $\mathrm{Ci}(p<0.001)$. These two results show that, even after 15 days, the mucosa had no recovered, exhibiting a nutritional deficit that was reflected in the low weight of the animals in group $\mathrm{Si}$ relative to group $\mathrm{Ci},(p<0.001)$. The length (height) of the villi in the SL and CL groups showed a highly significant difference, with longer villi in the CL group $(p<0.001)$. Even so, the mean height of the villi of the
SL rats was much larger than that group Si $(p<0.001)$, showing that this supplement had some ability to stimulate the proliferation of enterocytes, affecting positively the weight of the animals supplemented with lactoferrin $(p<0.001)$. This result also shows that the activity of lactoferrin in vivo may be similar to that demonstrated by Oguchi et al. [9] in vitro. Similar results were obtained by Wang et al. [38] in his study of pigs supplemented with $1 \mathrm{~g} / \mathrm{kg}$ lactoferrin. Although, the villi in group CL are only slightly longer than villi of group $\mathrm{Ci}$, without statistical significance, this result proves more consistent with the findings from the literature, which clearly demonstrates that there are highly effective mechanisms for maintaining the homeostasis of the intestinal epithelium [28-30]. The same is valid, therefore, when comparing the depth of the crypts in these two groups and also, in groups CL and SL, which showed no difference in crypt depth, even though the villus height was significantly higher in group CL. This leads us to believe that, at a given length of the villi, there is a partial inhibitory action on mitosis in the crypts, by control mechanisms mentioned above.

\subsection{Myofibroblasts of the Intestinal Pericrypt Sheath}

Myofibroblasts play a crucial role in the healing process and regeneration of the skin and there are numerous studies that seek to demonstrate the role of these cells in the gastrointestinal tract. Some show their beneficial features [39-43] and others cite harmful activities [44-46].

Subepithelial myofibroblasts, in a sheath around of the intestinal crypts, called "peri-crypt myofibroblasts" have been in to be responsible for the proliferation of villus enterocytes, secreting factors that stimulate mitosis in the crypts $[43,47]$. These cells are also considered important in the mechanism coordinating the crypt-villus unit. It is believed that the pericrypt myofibroblasts, which form a sheet underlying the intestinal epithelium, may modulate intestinal epithelial cell proliferation and differentiation, increase the resistance of lumen-blood barrier and modulate epithelial secretory responses to various agonists, such as acetylcholine or prostaglandins [30]. Shao and Sheng [43], in an experiment with mice, have demonstrated the important role of subepithelial myofibroblasts in regulating the composition of the microenvironment for regeneration of the intestinal epithelium, showing that on receiving extracellular stimuli, these cells produce a variety of epidermal growth factors, including amphiregulin (Areg), which stimulate the growth of intestinal epithelium through a paracrine pathway. Growth factors secreted by myofibroblasts have three actions: starting or increasing cell motility, inducing proliferation and inducing terminal differentiation of cells, even leading to apoptosis. These factors may act on the myofibro- 
blasts themselves, in an autocrine manner, or in a paracrine manner on epithelial or parenchymal cells, in tissue repair [48].

Tsai et al. [49], in an experiment with mice, found that Glucagon-Like Peptide 2 (GLP-2), a hormone produced by endocrine cells in the gastrointestinal tract, stimulates intestinal growth, increasing the proliferation of crypt enterocytes. Also working with mice, Orskov et al. [39] concluded that GLP-2 acts by binding to a receptor on intestinal myofibroblasts. These cells secrete various growth factors, one of which is KGF, which may be responsible for the growth of the villi of the colon and in particular the proliferation of goblet cells.

In our experiment, we observed that lactoferrin stimulated a significant increase in the number and size of myofibroblasts. The comparison between groups $\mathrm{Si}$ and $\mathrm{Ci}$ showed that the type of diet protein did not influence the number and size of myofibroblasts $(p>0.05)$, thus, neither the antigenicity of soy protein nor antinutritional factors influenced the mechanisms of proliferation and/or stimulation of myofibroblasts. This means that the role of myofibroblasts in promoting apoptosis of enterocytes [48], is very subtle and that villous atrophy is due more to the discard of the cells in the intestinal lumen.

Despite a significant increase in the number of myofibroblasts in group CL relative to group $\mathrm{Ci}(p<0.001)$ showing the effect of lactoferrin, the comparison between CL and SL showed that NMF was significantly higher for the soy group, so that there must be some synergistic effect between lactoferrin and another factor, when the mucosa is atrophied and consequently there is a need for more intense stimulation of enterocytes proliferation. Various cytokines and growth factors are cited by Powell et al. [48] as activators or stimulating the proliferation of myofibroblasts. One of these factors is referred to as EGF (Epidermal Growth Factor). Hagiwara et al. [25] showed a synergy between lactoferrin and EGF in cell proliferation, in a culture of rat intestinal cells.

Comparing the groups SL and $\mathrm{Si}$, we found highly significant values for the activity of lactoferrin, increasing both for the number and size of myofibroblasts, indicating that this protein has a really strong effect on these cells, which was also reflected in the proliferation of villous enterocytes. This result is consistent with findings for other proteins, such as endothelin [41], TSH [50], myostatin [51] and leptin [52].

\section{CONCLUSION}

Lactoferrin, administered orally at a dose of $200 \mathrm{mg} /$ $\mathrm{kg} /$ day to rats subjected to atrophy of the intestinal mucosa, increases the number and size of the pericrypt myofibroblasts and rapidly stimulates the regeneration of atrophied villi. Therefore, supplementation with this pro- tein may be valuable for individuals suffering atrophy of the mucosa by antimitotic substances or sudden changes in diet.

\section{ACKNOWLEDGEMENTS}

The authors acknowledge the careful proofreading of the text by Timothy John C. Roberts (MSc).

\section{REFERENCES}

[1] Thomson, A.B.R. and Keelan, M. (1986) The development of the small intestine. Canadian Journal of Physiology and Pharmacology, 64, 13-29.

doi:10.1139/y86-003

[2] Thomson, A.B.R., Keelan, M. and Wild, G.E. (1996) Nutrients and intestinal adaptation. Clinical \& Investigative Medicine, 19, 331-345.

[3] Li, D.F., Nelssen, J.L. and Reddy, P.G. (1990) Transient hipersensitivity to soybean meal in the early-weaned pig. Journal of Animal Science, 68, 1790-1799.

[4] Allee, G.L. and Touchette, K.J. (1999) Efectos de la nutricion sobre la salud intestinal y el crescimiento de lechones. Avances en Nutrición y Alimentación Animal, 125, 144.

[5] Caruso, M. and Demonte, A. (2005) Histomorfometria do intestino delgado de ratos submetidos a diferentes fontes Protéicas. Archives of Animal Nutrition, 16, 131-136.

[6] Vorland, L.H. (1999) Lactoferrin: A multifunctional glycoprotein. Acta Pathologica, Microbiologica et Immunologica Scandinavica, 107, 971-981.

[7] Suzuki, Y.A. and Lonnerdal, B. (2002) Characterization of mammalian receptors for lactoferrin. Biochemistry and Cell Biology, 80, 75-80. doi:10.1139/001-228

[8] Chen, J., Wu, J.J. and Li, J. (2006) Lactoferrin promotes human skin keratinocyte proliferation. 19th Annual Symposium on Advanced Wound Care, San Antonio.

[9] Oguchi, S., Walker, W.A. and Sanderson, I.R. (1995) Iron saturation alters the effect of lactoferrin on the proliferation and differentiation of human enterocytes (Caco-2 cells). Biology of the Neonate, 67, 330-339. doi:10.1159/000244182

[10] Schottstedt, T., Muri, C., More, L.C., Philipona, C., Hammon, H.A. and Blum, J.W. (2005) Effects of feeding Vitamin A and lactoferrin on epithelium of lymphoid tissues of intestine of neonatal calves. Journal of Dairy Science, 88, 1050-1061. doi: 10.3168/jds.S0022-0302(05)72773-9

[11] Yanaihara, A., Toma, Y., Saito, H. and Yanaihara, T. (2000) Cell proliferation effect of lacoferrin in human endometrial stroma cells. Molecular Human Reproduction, 6, 469-473. doi:10.1093/molehr/6.5.469

[12] Cornish, J., Callon, K.E., Naot, D., Palmano, K.P., Banovic, T., Bava, U., Watson, M., Lin, J.M., Tong, P.C., Chen, Q., Chan, V.A., Reid, H.E., Fazzalari, N., Baker, H.M., Baker, E.N., Haggarty, N.W., Grey, A.B., Ian, R. and Reid, I.R. (2004) Lactoferrin is a potent regulator of bone cell 
activity and increases bone formation in vivo. Endocrinology, 145, 4366-4374. doi:10.1210/en.2003-1307

[13] Esaguy, N., Freire, O., Van Embden, J.W. and Aguas, A.P. (1993) Lactoferrin triggers in vitro proliferation of T cells of Lewis rats submitted to mycobacteria-induced adjuvant arthritis. Scandinavian Journal of Immunology, 38, 47152. doi:10.1111/j.1365-3083.1993.tb01706.x

[14] Norrby, K. (2004) Human apo-lactoferrin enhances angiogenesis mediated by vascular endothelial growth factor A in vivo. Journal of Vascular Research, 41, 293-304. doi:10.1159/000078927

[15] Fritsch, C., Swietlicki, E.A, Lefebvre, O., Kedinger, M., Iordanov, H., Levin, M.S. and Rubin, D.C. (2002) Epimorphin expression in intestinal myofibroblasts induces epithelial morphogenesis. The Journal of Clinical Investigation, 110, 1629-1641.

[16] Reeves, P.G., Nielsen, F.H. and Fahey, G.C. (1993) AIN93 purified diets for laboratory rodents: Final report of the American Institute of Nutrition ad hoc writing committee on the reformulation of the AIN-76A rodent diet. Journal of Nutrition, 123, 1939-1951.

[17] National Research Council (1985) Guide for care and use of laboratory animals. National Academy of Sciences, Washington.

[18] Togawa, J.-I., Nagase, H., Tanaka, K., Namori, M., Umezawa, T., Nakajima, A., Naito, M., Sato, S., Saito, T. and Sekihara, H. (2002) Oral administration of lactoferrin reduces colitis in rats via modulation of the immune system and correction of cytokine imbalance. Journal of Gastroenterology and Hepatology, 17, 1291-1298. doi:10.1046/j.1440-1746.2002.02868.x

[19] Wakabayash, H., Kurokawa, M., Shin, K., Teraguchi, S., Tamura, Y. and Shiraki, K. (2004) Oral lactoferrin prevents body weight loss and increases cytokine responses during herpes simplex virus type 1 infection of mice. Bioscience, Biotechnology, and Biochemistry, 68, 537-544. doi:10.1271/bbb.68.537

[20] Varadhachary, A. (2004) Oral lactoferrin inhibits growth of established tumors and potentiates conventional chemotherapy. International Journal of Cancer, 111, 398403. doi:10.1002/ijc. 20271

[21] Shin, K., Wakabayashi, H., Koji, K., Yamauchi, Y., Teraguchi, S., Tamura, Y., Kurokawa, M. and Shiraki, K. (2005) Effects of orally administered bovine lactoferrin and lactoperoxidase on influenza virus infection in mice. Journal of Medical Microbiology, 54, 717-723. doi:10.1099/jmm.0.46018-0

[22] Hsu, S.M., Raine, L. and Fanger, H. (1981) Use of avidin-biotin-peroxidase complex $(\mathrm{ABC})$ in immunoperoxidase techniques: A comparison between $\mathrm{ABC}$ and unlabeled antibody (PAP) procedure. Journal of Histochemistry \& Cytochemistry, 29, 557-580. doi:10.1177/29.4.6166661

[23] Sanchez, L., Miguel Calvo, M. and Brock, J.H. (1992) Biological role of lactoferrin. Archives of Disease in Childhood, 67, 657-661. doi:10.1136/adc.67.5.657

[24] Stevanato, M.B. (2005) Estudo da eficiência da lactoferrina como conservante em formulações semi-sólidas para produtos cosméticos e farmacêuticos. Ph.D Thesis, Uni- versidade de São Paulo, Ribeirão Preto.

[25] Hagiwara, T., Shinoda, I., Fukuwatar, Y. and Shimamura, S. (1995) Effects of lactoferrin and its peptides on proliferation of rat intestinal epithelial cell line, IEC-18, in the presence of epidermal growth factor. Bioscience, Biotechnology, and Biochemistry, 59, 1875-1881. doi:10.1271/bbb.59.1875

[26] Kilshaw, P.J. and Slade, H. (1982) Villus atrophy and crypt elongation in the small intestine of preruminant calves fed with heated soyabean flour or wheat glúten. $R e$ search in Veterinary Science, 33, 305-308.

[27] Conneely, O.M. (2001) Antiinflammatory activities of lactoferrin. Journal of the American College of Nutrition, 20, 389S-395S.

[28] May, R.J., Quaroni, A., Kirsch, K. and Isselbacher, K.J. (1981) A villous cell-derived inhibitor of intestinal cell proliferation. American Journal of Physiology, 24, G520G527.

[29] Göke, M., Kanai, M. and Podolsky, D.K. (1998) Intestinal fibroblasts regulate intestinal epithelial cell proliferation via hepatocyte growth factor. American Journal of Physiology-Gastrointestinal and Liver Physiology, 274, G809G818.

[30] Neunlist, M., Aubert, P., Bonnaud, S., Van Landeghem, L., Coron, E., Wedel, T., Naveilhan, P., Ruhl, A., Lardeux, B., Savidge, T., Paris, F. and Galmiche, J.P. (2007) Enteric glia inhibit intestinal epithelial cell proliferation partly through a TGF-b1 dependent pathway. American Journal of Physiology - Gastrointestinal and Liver Physiology, 292, G231-G241. doi:10.1152/ajpgi.00276.2005

[31] Wells, C.L. and Rhame, F.S. (1990) Effect of oral dextran sulfate on the mouse intestinal tract. Journal of Acquired Immune Deficiency Syndromes, 3, 361-365.

[32] Wells, C.L., Maddaus, M.A., Reynolds, C.M., Jechorek, R.P. and Simmons, R.L. (1987) Role of anaerobic flora in the translocation of aerobic and facultatively anaerobic intestinal bacteria. Infection and Immunity, 55, 26892694.

[33] King, M.R., Morel, P.C.H., Revell, D.K., Pluske, J.R. and Birtles, M.J. (2008) Dietary bovine colostrum increases villus height and decreases small intestine weight in early-weaned pigs. Asian-Australasian Journal of Animal Sciences, 21, 567-573.

[34] Lee, D.N., Chang, W.F., Yu, I.T., Chiou, P.W.S. and Weng, C.F. (2008) Effects of diets supplemented with recombinant epidermal growth factor and glutamine on gastrointestinal tract development of early-weaned piglets. Asian-Australasian Journal of Animal Sciences, 21, 582589.

[35] Read-Snyder, J., Edens, F.W., Cantor, A.H., Pescatore, A.J. and Pierce, J.L. (2009) Effect of dietary selenium on small intestine villus integrity in reovirus-challenged broilers. International Journal of Poultry Sciences, 8, 829835. doi:10.3923/ijps.2009.829.835

[36] García, V., Catalá-Gregori, P., Hernández, F., Megías, M.D. and Madrid, J. (2007) Effect of formic acid and plant extracts on growth, nutrient digestibility, intestine mucosa morphology, and meat yield of broilers. The Journal of Applied Poultry Research, 16, 555-562. 


\section{doi:10.3382/japr.2006-00116}

[37] Asfar, S., Abdeen, S., Dashti, H., Khoursheed, M., HilalAl-Sayer, H. and Mathew, M. (2003) Effect of green tea in the prevention and reversal of fasting-induced intestinal mucosal damage. Nutrition, 19, 536-540. doi:10.1016/S0899-9007(02)01097-3

[38] Wang, Y., Shan, T., Xu, Z., Liu, J. and Feng, J. (2006) Effect of lactoferrin on the growth performance, intestinal morphology, and expression of PR-39 and protegrin-1 genes in weaned piglets. Journal of Animal Science, 84, 2636-2641. doi:10.2527/jas.2005-544

[39] Ørskov, C., Hartmann, B., Poulsen, S.S., Thulesen, J., Hare, K.J. and Holst, J.J. (2005) GLP-2 stimulates colonic growth via KGF, released by subepithelial myofibroblasts with GLP-2 receptors. Regulatory Peptides, 124, 105-112. doi:10.1016/j.regpep.2004.07.009

[40] Powell, D.W., Adegboyega, P.A, Di Mari, J.F. and Mifflin, R.C. (2005) Epithelial cells and their neighbors I. Role of intestinal myofibroblasts in development, repair, and cancer. American Journal of Physiology - Gastrointestinal and Liver Physiology, 289, G2-G7. doi:10.1152/ajpgi.00075.2005

[41] Nishida, T., Tsuji, S., Kimura, A., Tsuji, M., Ishii, S., Yoshio, T., Shinzaki, S.I., Egawa, S., Irie, T., Yasumaru, M., Iijima, H., Murata, H., Kawano, S. and Hayashi, N. (2006) Endothelin-1, an ulcer inducer, promotes gastric ulcer healing via mobilizing gastric myofibroblasts and stimulates production of stroma-derived factors. American Journal of Physiology-Gastrointestinal and Liver Physiology, 290, G1041-G1050. doi:10.1152/ajpgi.00462.2005

[42] Saada, J.I., Pinchuk, I.V., Barrera, C.A., Adegboyega, P.A., Suarez, G., Mifflin, R.C., Di Mari, J.F., Victor, E., Reyes, V.E., Don, W. and Powell, D.W. (2006) Subepithelial myofibroblasts are novel nonprofessional APCs in the human colonic mucosa. The Journal of Immunology, 177, 5968-5979.

[43] Shao, J. and Sheng, H. (2010) Amphiregulin promotes intestinal epithelial regeneration: Roles of intestinal subepithelial myofibroblasts. Endocrine Journal, 151, 37283737. doi:10.1210/en.2010-0319

[44] Jobson, T.M., Billington, C.B. and Hall, I.P. (1998) Regulation of proliferation of human colonic subepithelial myofibroblasts by mediators important in intestinal inflammation. The Journal of Clinical Investigation, 101,

\section{0-2657. doi:10.1172/JCI1876}

[45] Illemann, M., Hansen, U., Nielsen, H.J., Andreasen, P.A., Høyer-Hansen, G., Lund, L.R., Danø, K. and Nielsen, B.S. (2004) Leading-edge myofibroblasts in human colon câncer express plasminogen activator inhibitor-1. American Journal of Clinical Pathology, 122, 256-265. doi:10.1309/F32XWQ20T568H8VP

[46] Shao, J. (2006) Roles of myofibroblasts in prostaglandin E2-stimulated intestinal epithelial proliferation and angiogenesis. Cancer Research, 66, 846-855. doi:10.1158/0008-5472.CAN-05-2606

[47] Brittan, M., Hunt, T., Jeffery, R., Poulsom, R., Forbes, S.J., Hodivala-Dilke, K., Goldman, J., Alison, M.R. and Wright, N.A. (2002) Bone marrow derivation of pericryptal myofibroblasts in the mouse and human small intestine and colon. Gastroenterology and Hepatology Journals, 50, 752757.

[48] Powell, D.W., Mifflin, R.C., Valentich, J.D., Crowe, S.E., Saada, J.I. and West, A.B. (1999) Myofibroblasts: Paracrine cells important in health and disease. American Journal of Physiology-Gastrointestinal and Liver Physiology, 277, C1-C19.

[49] Tsai, C.H., Hill, M., Asa, S.L., Brubaker, P.L. and Drucker, D.J. (1997) Intestinal growth-promoting properties of glucagon-like peptide-2 in mice. American Journal of Physiology, 73, E77-E84.

[50] Drobnik, J., Ciosek, J., Slotwinska, D., Stempniak, B., Zukowska, D., Marczynski, A., Tosik, D., Bartel, H., Dabrowski, R. and Szczepanowska, A. (2009) Experimental hypothyroidism increases content of collagen and glycolsaminoglycans in the heart. Journal of Physiology and Pharmacology, 60, 57-62.

[51] Cantini, L.P., Ferrini, M.G., Vernet, D., Magee, T.R., Qian, A., Gelfand, R.A., Rajfer, J. and Gonzalez-Cadavid, N.F. (2008) Profibrotic role of myostatin in peyronie's disease. Journal of Sexual Medicine, 5, 1607-1622. doi:10.1111/j.1743-6109.2008.00847.x

[52] Nakamura, M., Akiba, Y., Matsui, H., Tsuchimoto, K. and Ishii, H. (2003) Interaction of leptin with gastric myofibroblast transdifferentiation in Hp-infected Mongolian gerbils: Effect of rebamipide. Alimentary Pharmacology \& Therapeutics, 18, 99-105. doi:10.1046/j.1365-2036.18.s1.11.x 